\title{
Recent Updates in Intrastromal Corneal Rings
}

\author{
AHMED E. ABD ELRAHMAN AHMED, M.Sc.; ADEL HASSOUNA, M.D. and \\ HASSAN METWALLY, M.D.
}

The Department of Ophthalmology, Faculty of Medicine, Al-Azhar University

\begin{abstract}
Background: Keratoconus is a disorder that causes myopia and irregular astigmatism by causing gradual corneal steepening, usually below the cornea's center, as well as eventual central and para-central corneal thinning.

Aim of Study: The objective of this study is to evaluate the efficacy of femtosecond laser-assisted intrastromal corneal ring segment implantation in the management of keratoconus.

Patients and Methods: A study of 40 keratoconus patients' eyes was conducted retrospectively. The research was conducted at the AL-Azhar University Hospital's outpatient clinic during the period between January 2020 till January 2021.

Results: Non-significant difference in patient satisfaction had been reported in the study group versus the control group. $80 \%$ of participants of two segment group were satisfied by the results compared to $70 \%$ of participants of the 355 keraring group.

Conclusion: Intrastromal corneal ring segments have the benefits of being reversible, changeable, and relatively safe. It is a low-cost technique which prevents or merely postpones penetrating keratoplasty in keratoconic patients.
\end{abstract}

Key Words: Keratoconus - Intrastromal corneal ring - Kerarings - Astigmatism - Femtosecond laser.

\section{Introduction}

THE clinical findings of Keratoconus include corneal steepening, stromal thinning, conical protrusion, cone displacement, deep stromal stress lines (Vogt's striae), prominent corneal nerves, iron deposition ring at the cone's base (Fleischer ring), sub-epithelial corneal scarring and acute hydrops in advanced cases [1].

Non-surgical treatment modalities are initially tried that include spectacles for correction of astigmatism and myopia, soft lenses of toric design, and rigid gas permeable lenses for more advanced cases. These comprise multicurve spherical-based lenses, aspheric and biaspheric lenses, and hybrid

Correspondence to: Dr. Ahmed E. Abd Elrahman Ahmed, E-Mail: Ahmed Ragab@gmail.com lenses with a hard central segment and a soft peripheral skirt. For very advanced cases hard contact lenses are used [2,3].

Current Surgical options include: Intra stromal corneal ring segments (Intacs, Ferrara, and Kera rings), Ultraviolet-A/Riboflavin corneal crosslinking (CR3), Lenticular (lens) refractive surgery including Phakic IOL implantation, and refractive lens exchange with regular or toric intraocular lens implantation, thermokeratoplasty, corneal refractive surgeries usually in combination with cross-linking and corneal transplantation (or grafting) including penetrating keratoplasty and Lamellar keratoplasty [4].

Several methods for assessing corneal shape and assisting in keratoconus diagnosis and followup have been developed and used. These include Placido disc, Keratometry, Photokeratoscope, Computerized videokeratoscopy (corneal topography), slit-scanning topography (Orbscan) and Scheimpflug imaging (Pentcam) [5].

Keratoconus is corrected with corneal ring segments. They are made up of two polymethyl methacrylate (PMMA) segments that, when surgically implanted into the periphery of the corneal stroma, flatten the central anterior corneal curvature via increasing the cornea's peripheral thickness [6]

The goal of corneal ring implantation is not to eradicate corneal illness, but rather to reduce the corneal abnormalities linked with it, decrease the central corneal curvature, improve the visual acuity in afflicted sufferers to a satisfactory level, and remove or at minimum, postpone the necessity for a corneal graft [6].

\section{Aim of the study:}

The purpose of this work is to evaluate the femtosecond laser assisted intrastromal corneal ring segment implantation for treating keratoconus. 


\section{Patients and Methods}

This is a retrospective study including 40 keratoconus patients' eyes. Before being enlisted in the research, the participants had been told about the study's purpose and signed informed consent. The research has been conducted at the outpatient clinic of Al-Azhar University Hospital.

We evaluated the patients and recorded the first time to notice any change in visual acuity, any history of previous eye disease, progression of the condition if found in the form of diminution of vision, frequency of refractive error check-up, contact lenses usage and its tolerability, Visual requirements for work and daily life activities, satisfaction of their current visual acuity and their expectations for the postoperative outcome.

We also examined the patients for visual acuity using Landolt's chart, Cycloplegic refraction objectively by Topcon autorefractometer, and Keeler streak retinoscopy. We used Slit lamp biomicroscopy (Topcon) to detect keratoconus symptoms, e.g., prominent corneal nerves, corneal scarring, conical protrusion, stromal thinning, Fleischer's ring, and Vogt's striae. We also performed fundus examination: Keeler indirect ophthalmoscope was used to exclude retinal pathology. Keeler direct ophthalmoscope to detect Charleaux's sign or oil droplet sign. Intraocular pressure was measuered by Shinnippon applanation tonometer to detect IOP. And Corneal Imaging and topography by Oculus Pentacam with Scheimpflug imaging. We chose the segments based on the nomogram supplied by the manufacturer.

The Intrastromal corneal ring segment (keraring) has been utilized in that researchusing the following characteristics: Made of PMMA CQacrylic segments, Implantation depth is at $70 \%$ depth of cornea, The internal diameter of kera segment is $4.4-5.4 \mathrm{~mm}$ and the external diameter 5.6-6.4mm for 5.0-mm optical zone. The crosssection of the segment is triangular, with a base of 600 for all thicknesses and diameters. Each segment's end has a $0.20 \mathrm{~mm}$ hole. An arc length of $160^{\circ}$ and $355^{\circ}$. Thickness of the segments (150 $\mathbf{m}, 00 \mathrm{~m}, 050 \mathrm{~m}, 00 \mathrm{~m}$, and $350 \mathrm{~m})$ While in 355 ring thickness is 200 and 300 r.e.

Before the operation, topical antibiotics were administered into the eye 5 times a day the day before the operation and every hour on the day of the operation. The entire procedure took place under local anaesthesia (oxybuprocaine chloride) instilled into the conjunctival sac and skin sterili- zation by Betadine $10 \%$ solution. To widen the palpebral fissure, a wire eye speculum was inserted. Also, ocular irrigation with a $5 \%$ solution of Betadine.

A femtosecond laser (Wavelight-FS 200, Alcon Surgical, Inc.) was used to create tunnels during the surgical procedures. The femtosecond laser applanated the cornea, fixated the eye, and maintained a perfect distance between the laser's head and the tunnel location's focal point with the help of a disposable glass lens. The ICRS's midsection was grasped using forceps and lifted from the casing in the next step. Sinskey hooks were used to reopen the original incision, and the ring segment was then rolled slightly superiorly to reach the correct entry angle. The forceps were released once the leading edge was put into the pocket and half of the segment had entered the tunnel. The Sinskey hook was then used to push the rest of the segment into the tunnel.

It was recommended to all the patients to continue in the stated local antibiotic therapy. Tobradex, a topical mixture of tobramycin and dexamethasone eye drops, was recommended 5 times a day for only 5 days. For 3 months, topical artificial tear eye drops (Refresh Tears) were prescribed 4 times each day. Patients have been instructed not to rub their eyes too hard. Following 48 hours, the contact lenses have been removed.

Patients have been checked on day one, a week, one month, three months, and six months after surgery to see if their vision has improved. Photophobia, glare, or halos are all common complaints.

SPSS version 19 was used to collect, tabulate, and statistically analyze all data. Continuous quantitative data has been represented as mean \pm SD and median (range), while categorical qualitative data has been represented as absolute and relative frequency (number) (percentage). The KolmogorvSmirnov test was used to determine the normality of continuous data. Independent samples Student's $t$-test has been utilized to compare two groups of normally distributed quantitative continuous data. The Mann-Whitney test has also been employed to compare two groups of quantitative continuous data that were not normally distributed. The Chisquare test has been employed to compare categorical data. All tests were two-sided; $p$-values of $<0.05$ were deemed statistically significant (S), a $p$-value of $<0.001$ was deemed highly statistically significant (HS), and a $p$-value of $\geq 0.05$ was deemed statistically insignificant (NS). 


\section{Results}

Mean age in 355 keraring group was $29.5 \pm$ 6.20 and in two segments group was $28.5 \pm 5$.8. In terms of age, there was no significant difference between the groups tested. In terms of sex, however, there was a significant difference between them (Table 1).

Table (1): A comparison of demographic data among the groups studied.

\begin{tabular}{|c|c|c|c|}
\hline & $\begin{array}{l}355 \text { keraring } \\
\text { group }(n=20)\end{array}$ & $\begin{array}{l}\text { Two segment } \\
\text { group }(n=20)\end{array}$ & $\begin{array}{c}p- \\
\text { value }\end{array}$ \\
\hline \multicolumn{4}{|l|}{ Age: (years) } \\
\hline Mean \pm SD & $29.5 \pm 6.20$ & $28.5 \pm 5.8$ & $>0.05$ \\
\hline Range & $18-41$ & $18-43$ & \\
\hline Sex: & No. $\%$ & No. $\%$ & $p$ \\
\hline Female & 12 & 0 & $<0.001$ \\
\hline Male & $8 \quad 40$ & $20 \quad 100$ & \\
\hline
\end{tabular}

Presurgical best corrected visual acuity was not significantly different between the examined groups $(p>0.05)$, but postsurgical BCVA in the two segment group was significantly greater than in 355 ring group. When compared to presurgical BCVA, postsurgical BCVA in both groups was significantly greater $(0.47,0.72$ versus 0.19 and 0.16 in the 355 keraring and two-segment groups, respectively) (Table 2).

Table (2): Comparison of the studied groups' best corrected visual acuity.

\begin{tabular}{llll}
\hline & $\begin{array}{c}\text { 355 keraring } \\
\text { group }(\mathrm{n}=20)\end{array}$ & $\begin{array}{l}\text { Two segment } \\
\text { group }(\mathrm{n}=20)\end{array}$ & $\begin{array}{c}p \text { - } \\
\text { value }\end{array}$ \\
\hline $\begin{array}{l}\text { Preoperative } \\
\text { BCVA: }\end{array}$ & & & \\
$\quad$ Mean \pm SD & $0.18 \pm 0.19$ & $0.17 \pm 0.14$ & 0.872 \\
Median & 0.10 & 0.1 & $(\mathrm{NS})$ \\
Range & $0.0-0.5$ & $0.05-0.5$ & \\
Postoperative & & & \\
BCVA: & & & \\
$\quad$ Mean \pm SD & $0.47 \pm 0.21$ & $0.72 \pm 0.11$ & $<0.001^{* *}$ \\
Median & 0.45 & 0.70 & \\
Range & $0.1-1$ & $0.5-0.9$ & \\
\hline
\end{tabular}

In terms of pre and postoperative $\mathrm{k} 1$, there were no significant differences among the studied groups. It was found that postoperative $\mathrm{k} 1$ reading in two segment group was lower than that of 355 keraring group. When compared to presurgical $\mathrm{k} 1$, both groups' postsurgical $\mathrm{k} 1$ was significantly lower (42.7, 42.6 versus 48.9 and 47.8 in the 355 keraring and two segment groups, respectively) (Table 3 ).
Table (3): Comparison of k1 among the studied groups.

\begin{tabular}{llll}
\hline & $\begin{array}{c}355 \text { keraring } \\
\text { group }(\mathrm{n}=20)\end{array}$ & $\begin{array}{c}\text { Two segment } \\
\text { group }(\mathrm{n}=20)\end{array}$ & $\begin{array}{c}p \text { - } \\
\text { value }\end{array}$ \\
\hline $\begin{array}{l}\text { Preoperative } \\
k 1:\end{array}$ & & & \\
$\quad$ Mean \pm SD & $48.9 \pm 4.65$ & $47.8 \pm 3.74$ & $>0.05$ \\
$\quad$ Range & $43.6-61.5$ & $42.5-55.5$ & \\
Postoperative & & & \\
& & & \\
$\quad$ Mean \pm SD & $42.7 \pm 4.759$ & $42.6 \pm 10.5$ & $>0.05$ \\
$\quad$ Range & $34.5-53.5$ & $0.7-55$ & \\
\hline
\end{tabular}

NS: Non-significant difference.

In terms of postoperative $\mathrm{K} 2$, there were no significant differencesbetween the studied groups, but there were significant differences between them preoperatively. When compared to preoperative $\mathrm{K} 2$, postoperative $\mathrm{K} 2$ was significantly lower in both groups $(46.3,49.1$ versus 55.1, 52.2 in the 355 keraring and two segment groups, respectively) (Table 4).

Table (4): Comparison of $\mathrm{k} 2$ among the studied groups.

\begin{tabular}{ccc}
355 keraring & Two segment & $p$ - \\
group $(\mathrm{n}=20)$ & group $(\mathrm{n}=20)$ & value \\
\hline
\end{tabular}

Preoperative

$\begin{array}{llll}\text { Mean } \pm \text { SD } & 56.2 \pm 4.70 & 52.1 \pm 3.1 & <0.003 \\ \text { Median } & 48-65.5 & 47.2-55.5 & \\ \text { Range } & & & \end{array}$

Postoperative

kl:

\begin{tabular}{llll} 
Mean \pm SD & $46.3 \pm 5.10$ & $49.1 \pm 4.33$ & $>0.05$ \\
Median & $38.1-56.5$ & $44.5-58.1$ & \\
Range & & & \\
\hline
\end{tabular}

Paired $t$-test.

NS:Non-significant difference.

**: High significant difference.

In terms of satisfaction, there were no significant differences among the groups studied. $80 \%$ of participants in two segment groups were satisfied from the results compared to $70 \%$ in 355 keraring group (Table 5).

Table (5): Comparison of degree of satisfaction among the studied groups.

\begin{tabular}{lccccccc}
\hline & $\begin{array}{c}\text { 355 keraring } \\
\text { group }(\mathrm{n}=20)\end{array}$ & & \multicolumn{2}{l}{$\begin{array}{l}\text { Two segment } \\
\text { group }(\mathrm{n}=20)\end{array}$} & $\begin{array}{c}p \text { - } \\
\text { value }\end{array}$ \\
\cline { 2 - 3 } & No. & $\%$ & & No. & $\%$ & \\
\hline Satisfied & 14 & 70 & & 16 & 80 & $>0.05$ \\
Not satisfied & 6 & 30 & & 4 & 20 & \\
\hline
\end{tabular}

Criteria of satisfaction: Vision improvement, glare and night vision. 
In terms of the occurrence of complications, there were no significant differences among the studied groups (Table 6).

Table (6): Comparison of complications among the studied groups.

\begin{tabular}{llllll}
\hline & $\begin{array}{c}355 \text { keraring } \\
\text { group }(\mathrm{n}=20)\end{array}$ & $\begin{array}{l}\text { Two segment } \\
\text { group }(\mathrm{n}=20)\end{array}$ & $\begin{array}{c}p \text { - } \\
\text { value }\end{array}$ \\
\cline { 2 - 5 } & No. & $\%$ & No. & $\%$ & \\
\hline $\begin{array}{l}\text { Segment } \\
\text { displacement: }\end{array}$ & & & & & \\
$\quad$ Yes & 1 & 5 & 1 & 5 & $>0.05$ \\
No & 19 & 95 & 19 & 95 & \\
$\begin{array}{l}\text { Keratitis: } \\
\text { Yes }\end{array}$ & 4 & 20 & 3 & 15 & $>0.05$ \\
$\quad$ No & 16 & 80 & 17 & 85 & \\
$\begin{array}{l}\text { Segment } \\
\text { extrusion: }\end{array}$ & & & & & \\
$\quad$ Yes & 1 & 5 & 0 & 0 & $>0.05$ \\
$\quad$ No & 19 & 95 & 20 & 100 & \\
$\begin{array}{l}\text { Corneal } \\
\text { vascularization: }\end{array}$ & & & & & \\
$\quad$ Yes & 1 & 5 & 1 & 5 & $>0.05$ \\
$\quad$ No & 19 & 95 & 19 & 95 & \\
\hline
\end{tabular}

BCVA postoperatively was significantly higher in those underwent 355 keraring and were sphere when compared to two segments group ( 0.56 versus 0.35 respectively) (Table 7 ).

Table (7): A comparison of the studied groups' best corrected visual acuity (patients with more sphere than cylinder).

\begin{tabular}{|c|c|c|c|}
\hline & $\begin{array}{l}355 \text { keraring } \\
\text { group }(\mathrm{n}=12)\end{array}$ & $\begin{array}{l}\text { Two segment } \\
\text { group }(n=6)\end{array}$ & $\begin{array}{c}p- \\
\text { value }\end{array}$ \\
\hline \multicolumn{4}{|l|}{ Preoperative } \\
\hline \multicolumn{4}{|l|}{ BCVA: } \\
\hline Mean $\pm S D$ & $0.15 \pm 0.12$ & $0.12 \pm 0.06$ & $>0.05$ \\
\hline Median & 0.10 & 0.1 & \\
\hline Range & $0.01-0.5$ & $0.1-0.2$ & \\
\hline \multicolumn{4}{|l|}{ Postoperative } \\
\hline \multicolumn{4}{|l|}{ BCVA: } \\
\hline Mean $\pm S D$ & $0.56 \pm 0.12$ & $0.35 \pm 0.12$ & $0.001(\mathrm{~S})$ \\
\hline Median & 0.50 & 0.30 & \\
\hline Range & $0.4-0.9$ & $0.1-0.8$ & \\
\hline
\end{tabular}

BCVA postoperatively was significantly higher in those underwent two segments group and were cylinder when compared to 355 keraring $(0.665$ versus 0.47 respectively) (Table 8 ).
Table (8): A comparison of the studied groups' best corrected visual acuity (patients with more cylinder than sphere).

\begin{tabular}{llll}
\hline & $\begin{array}{c}355 \text { keraring } \\
\text { group }(\mathrm{n}=8)\end{array}$ & $\begin{array}{l}\text { Two segment } \\
\text { group }(\mathrm{n}=14)\end{array}$ & $\begin{array}{c}p \text { - } \\
\text { value }\end{array}$ \\
\hline Preoperative & & & \\
BCVA: & & & \\
$\quad$ Mean $\pm \mathrm{SD}$ & $0.18 \pm 0.11$ & $0.16 \pm 0.154$ & $>0.05$ \\
$\quad$ Median & 0.14 & 0.3 & \\
$\quad$ Range & $0.01-0.5$ & $0.05-0.5$ & \\
Postoperative & & & \\
BCVA: & & & \\
$\quad$ Mean \pm SD & $0.47 \pm 0.28$ & $0.66 \pm 0.18$ & $0.02(\mathrm{~S})$ \\
$\quad$ Median & 0.45 & 0.70 & \\
$\quad$ Range & $0.2-1$ & $0.4-0.9$ & \\
\hline
\end{tabular}

\section{Discussion}

Keratoconus is a vision-impairing disease that is characterized by stromal weakness accompanied with corneal protrusion, resulting in irregular astigmatism. Its specific cause is unknown. Keratoconus is thought to be caused by a variety of reasons [7]. The Femtosecond laser was used to create corneal tunnels, making the corneal ring implantation operation faster, easier, and safer with exact implantation depth [8]

Because visual function and vision quality are important components of postsurgical visual rehabilitation, it is critical to examine postsurgical changes in contrast sensitivity and aberrometry. Lamy et al., have reported the improvement of photopic contrast sensitivity at 2 years after standard Collagen corneal cross-linking [9]. In terms of surgery's effect on aberrations, two short-term studies have shown a lack of impact of standard collagen corneal cross-linking on higher-order aberrations (HOAs) [10]

Our findings revealed that there was no statistically significant difference between the examined groups in terms of presurgical best corrected visual acuity $(p>0.05)$, but postsurgical BCVA in the twosection group was significantly greater than inthe 355 ring group. When compared to presurgical $\mathrm{BCVA}$, postsurgical BCVA has been shown to be significantly greater in both groups $(0.47,0.72$ versus 0.19 and 0.16 in 355 keraring and two segment groups respectively).

As per the findings of this research, the femtosecond laser implantation of a 355-degree intrastromal corneal ring segment was successful as per the description of success identified by Jorge Alio et al., who identified successful surgery as one of the following features at 6 months following sur- 
gery: Either an advancement in one or more lines of uncorrected visual acuity (UCVA) or BCVA, or a reduction oftwo or more $\mathrm{D}$ of spherical equivalent. "Stable cases" have been classified as those with no significant shifts in corneal topography over a 12-month period preoperatively [11]

Additionally, the study revealed that there were no significant differences between the examined groups regarding pre and postoperative $\mathrm{k} 1$. It was found that postoperative $\mathrm{k} 1$ reading in two segment group was lower than that of 355 keraring group. When compared to presurgical $\mathrm{k} 1$, postsurgical $\mathrm{k} 1$ has been shown to be significantly decreased in both groups $(42.7,42.6$ versus 48.9 and 47.8 in 355 keraring and two segment groups respectively).

In contrary to our results, the $\mathrm{K}$ readings, which included the $\mathrm{K} \max , \mathrm{K}$ min, and $\mathrm{K}$ mean, altered significantly postoperatively. The study of Abdellah et al. indicated that the shift was statistically significant, implying that the rings have the ability to alter the convexity and geometry of the cornea. Nevertheless, because of the significant prevalence of ring extrusion accompanied by keratoconus advancement following ring explanation, the mean $\mathrm{K}$ values have been increased in subsequent followups [12].

The current study also found that there were no statistically significant differences between the examined groups in terms of postoperative $\mathrm{K} 2$, but there were significant differences between them preoperatively. When compared to presurgical K2, postsurgical K2 was significantly decreased in both groups (46.3, 49.1 versus 55.1 and 52.2 in 355 keraring and two segment groups respectively).

In another study by Kasumovic et al., the value of $\mathrm{K} 1$ reading before therapy was 48.8 diopters (D), which was statistically significantly less than the value of $\mathrm{K} 1$ three months after therapy was $46.30 \mathrm{D}(p=0.0006)$, and K1 reading one year after surgery was $47.20 \mathrm{D}(p=0.002)$. The $\mathrm{K} 2$ reading was $52.65 \mathrm{D}$ before the operation, 3 months after the procedure was $51.4,6$ months later $48.55 \mathrm{D}$, 12 months later $51.30 \mathrm{D}$. K2 readings are statistically reduced 6 months following therapy as compared to results 3 months following surgery $(p=0.014)$. But, when compared to the prior to surgery period, 12 months following surgery, K2 readings were significantly lower $(p=0.006)$ [13] .

In terms of satisfaction, our study found no significant differences between the groups tested. $80 \%$ of participants in two segment groups were satisfied from the results compared to $70 \%$ in 355 keraring group. According to Jadidi et al., all participants have been satisfied with Keraring $355^{\circ}$ implantation, which is consistent with the present research. Similarly, $86.7 \%$ of patients said they were moderately to extremely delighted with the outcomes on a scale of 0 to 5 for present total satisfaction [14]

The current study assessed the occurrence of complications between the examined groups and revealed that there was no statistically significant difference between them. The study of Zare et al., reported 3 eyes (10\%) that had ring exposure (extrusion), and 1 eye $(33.33 \%)$ had bacterial keratitis and ring exposure [15].

In addition to the above, the present study assessed which of the tested groups had the best corrected visual acuity (patients with more sphere than cylinder) and revealed that BCVA postoperatively was significantly higher in those whounderwent 355 keraring and were spherewhen compared to the two-segmentgroup ( 0.56 versus 0.35 respectively).

Among the groups studied, the best corrected visual acuity (patients with more cylinder than sphere) we found that BCVA postoperatively was significantly higher in those underwent two segments group and were cylinder when compared to 355 keraring ( 0.665 versus 0.47 respectively).

The ICRS surgery reduces myopia as well as regular and irregular astigmatism through regularizing the anterior corneal surface. The use of a femtosecond laser in this treatment provided additional benefits, including increased safety, precision, and ease of access by the surgeon [11,16]

Regarding the results in the study of Abdellah et al., the UCVA altered considerably following the procedure that is statistically significant [12] This was supported by the Jadidi study, which implanted 355-degree kerarings using a mechanical approach and a keratome: The UCVA enhanced from presurgical to postsurgical at 1 to 3 months, and the difference between 3 and 6 months indicated a statistically significant improvement [14]

Intrastromal corneal ring segments, on the other hand, provide an effective and safe treatment option for keratoconus patients who are unsuitable for other treatments. Although contact lenses aren't always efficient, particularly for patients with advanced keratoconus, operative treatment options including penetration keratoplasty and deep lamellar keratoplasty are more invasive and come with a moderate risk of complications or refusal. Ker- 
aring implantation is a practical option that offers good visual results [17]

Keratoconus treatment has evolved significantly in recent years. Cornea physicians may now undertake a variety of therapy techniques which may impede progression of the disease and change the cornea shape in keratoconus patients in a safe and efficient manner, resulting in optimal visual outcomes. Future advancements may increase the efficacy and safety of such treatments even more. Further research is required to give clinical evidence of their efficacy in the short and long term.

The use of a femtosecond laser to implant a 355-degree intracorneal keraring enhanced the visual, refractive, and topographic characteristics of keratoconus patients.

\section{Conclusion:}

Intrastromal corneal ring segments have the benefits of being possibly reversible, change able, and relatively safe. It is a low-cost technique which prevents or postpones penetrating keratoplasty in keratoconus patients. The use of a 355 ring in instances of central keratoconus with higher spherical error than a cylinder improved vision in all patients in both groups. Using two segments results in more cylinder errors than spherical errors.

More experimental and clinical research with further patients and lengthier follow-up are required to enhance the safety and predictability of the findings and assure their stability.

\section{References}

1- NADERAN M., SHOAR S., KAMALEDDIN M.A., RAJABI M.T. and NADERAN M.: Keratoconus clinical findings according to different classifications. Cornea, 34 (9): 1005-1011, 2015.

2- DOWNIE L.E. and LINDSAY R.G. Contact lens management of keratoconus. Clinical and Experimental Optometry, 98 (4): 299-311, 2015.

3- RICO-DEL-VIEJO L., GARCIA-MONTERO M., HERNÁNDEZ-VERDEJO J.L., GARCÍA- LÁZARO S. and GÓMEZ-SANZ F.J.: Nonsurgical procedures for keratoconus management. Journal of Ophthalmology, 9: $1-7,2017$.

4- ARNALICH-MONTIEL F., DEL BARRIO J.L.A. and ALIÓ J.L.: Corneal surgery in keratoconus: Which type, which technique, which outcomes; Eye and Vision, 3 (1): $2-5,2016$.
5- JAFARINASAB M.R., SHIRZADEH E., FEIZI S., KARIMIAN F. and AKABERI A.: Sensitivity and specificity of posterior and anterior corneal elevation measured by orbscan in diagnosis of clinical and subclinical keratoconus. Journal of Ophthalmic \& Vision Research, 10 (1): 10-15, 2015.

6- VEGA-ESTRADA A. and ALIO J.L.: The use of intracorneal ring segments in keratoconus. Eye and Vision, 3 (1): 8-12, 2016.

7- MILLODOT S.M., BLUMBERG S., ORTENBERG I., BEHRMAN S. and GORDON- SHAAG A.: Characteristics of 244 patients with keratoconus seen in an optometric contact lens practice. Clinical and Experimental Optometry, 96 (2): 219-224, 2013.

8- ERTAN A. and BAHADIR M.: Topography-guided vertical implantation of Intacs using a femtosecond laser for the treatment of keratoconus. J. Cataract Refract Surg., 33 (1): 148-151, 2007.

9- LAMY R., NETTO C.F., REIS R.G., PROCOPIO B. and PORCO T.C.: Effects of corneal cross-linking on contrast sensitivity, visual acuity, and corneal topography in patients with keratoconus. Cornea, 32: 591-6, 2013.

10- HASSAN Z., MODIS L., SZALAI E., BERTA A. and NEMETH G.: Scheimpflug imaged corneal changes on anterior and posterior surfaces after collagen cross-linking. Int. J. Ophthalmol., 7: 313-6, 2014.

11- ALIO J.L., BARRAQUER R., ESPERANZA S., MURTA J. and TEUS M.: Intrastromal corneal ring segments: How successful is the surgical treatment of keratoconus? Middle East African Journal of Ophthalmology, 21 (1): 3-9, 2014.

12- ABDELLAH M.M. and AMMAR M.G.: Femtosecond Laser Implantation of a 355-Degree Intrastromal Corneal Ring Segment in Keratoconus: A Three-Year Follow-Up; Journal of Ophthalmology, Article ID 6783181, P. 7, 2019.

13- KASUMOVIC S., RACIC-SAKOVIC A., KASUMOVIC A., PAVLJASEVIC S. and DURIC-COLIC B.: Assessment of the tomographic values in keratoconic eyes after collagen crosslinking procedure. Medical Archives, 69 (2): 91-94, 2015.

14- JADIDI K., MOSAVI S.A., NEJAT F., NADERI M. and JANANI L.: Intrastromal corneal ring segment implantation (keraring $355^{\circ}$ ) in patients with central keratoconus: 6-month follow-up. Journal of Ophthalmology, 916385. doi:10.1155/2015/916385, 2015.

15- ZARE M.A., HASHEMI H. and SALARI M.R.: Intracorneal ring segment implantationfor the management of keratoconus: Safety and efficacy. J. Cataract Refract Surg., 33 (11): 1886-91, 2007.

16- MAHMOOD H., VENKATESWARAN R.S. and DAXER A.: Implantation of a complete corneal ring in an intrastromal pocket for keratoconus. Journal of Refractive Surgery, 27 (1): 63-68, 2011.

17- ANDREANOS K.D., HASHEMI K., PETRELLI M. DROUTSAS K. and GEORGALAS I.: Keratoconus Treatment Algorithm. Ophthalmology and Therapy, 6 (2): 245 262, 2017. 


\section{الجلديل في زراعة الحلقات داخل بطانة القرنية

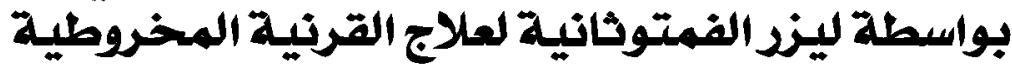

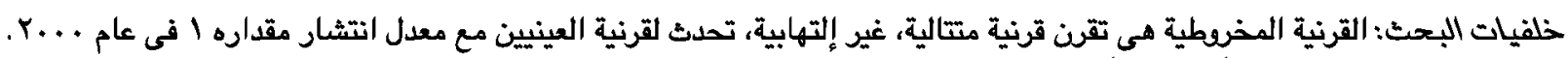

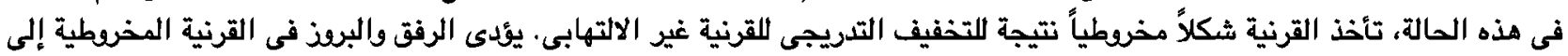

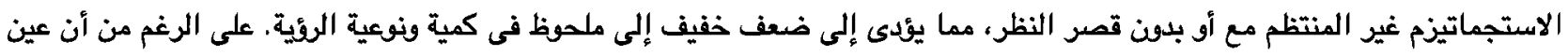
واحدة فقط قد تتأثر فى البداية، فإن هذا الاضطراب التدريجى يؤثثر فى النهاية على كلتا العينين.

الهدف من البحث: الهدف من هذه الدراسة هو تقييم فعالية نرع الجزء الحلقى القرنى داخل القرنية بمساعدة الليز فى إدارة القرنية

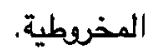

المرضى وطرق البحث: أجريت دراسة على عيون ·ع مريضاً القرنية المخروطية باثثر رجعى. أجرى البحث فى العيادة الخارجية لمستثفى

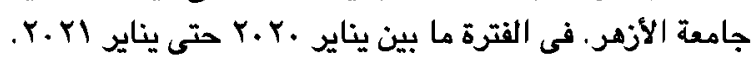

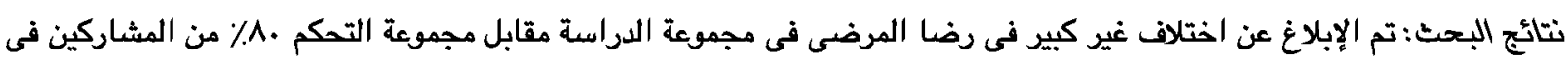

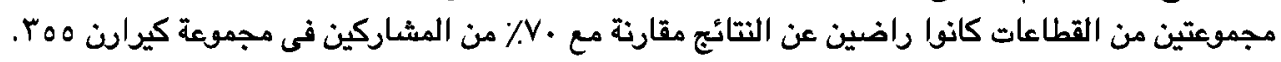

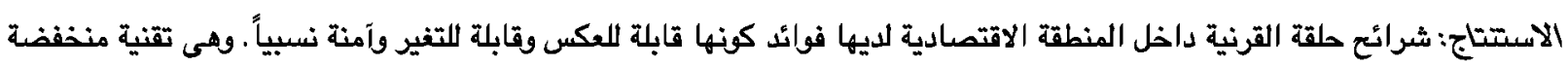
التكلفة تمنع أو تؤجل فقط اختراق رأب القرنية فى المرضى القرنين لاخلين. 